\title{
Thrombocytopenia in pregnant women
}

\author{
Monika Ruszala' ${ }^{1}$, Elzbieta Poniedzialek-Czajkowska ${ }^{1}\left(\mathbb{D}\right.$, Radzislaw Mierzynski $^{1}(\mathbb{D}$,

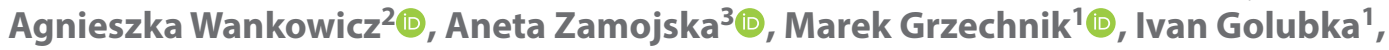

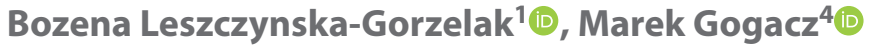 \\ ${ }^{1}$ Department of Obstetrics and Perinatology, Medical University of Lublin, Poland \\ 2University Children's Hospital, Chair and Department of Pediatrics, Pulmonary Diseases and Rheumatology, Lublin, Poland \\ ${ }^{3}$ Medical University of Lublin, Poland \\ ${ }^{4}$ II Department of Gynecology, Medical University of Lublin, Poland
}

\begin{abstract}
Thrombocytopenia is one of the two most common hematological problems in pregnant women. It is defined as the platelet (PLT) count below $150 \times 10^{3} / \mu \mathrm{L}$. Gestational incidental thrombocytopenia (GIT) represents about $75 \%$ of thrombocytopenia cases in pregnancy and it is believed that GIT is secondary to accelerated platelet destruction and increased plasma volume associated with pregnancy. The pregnancy complications such as preeclampsia and its most severe form - HELLP syndrome account for $20 \%$ cases of thrombocytopenia in pregnancy and primary immune thrombocytopenic purpura (ITP) - for 3-4 percent. During ITP, maternal antiplatelet antibodies can pass through the placenta and bind to fetal thrombocytes leading to the development of fetal thrombocytopenia which occurs in about $50 \%$ cases. Even if the maternal platelet count stabilizes, the estimated fetal and neonatal risk of thrombocytopenia in ITP is approximately $30 \%$. Other types of thrombocytopenia in pregnant women constitute 1-2\% of cases (disseminated intravascular coagulation, autoimmunological diseases, congenital, infection and drug-related, concomitant with blood neoplastic diseases). Although thrombocytopenia in pregnant women usually has a mild course, in case of a significant decrease in PLT count may lead to dangerous bleeding, especially when the platelet count falls below $20 \times 10^{3} / \mu \mathrm{L}$.

Since it is important to identify the cause of thrombocytopenia and to determine the risk for both the mother and the child, this paper presents the influence of maternal thrombocytopenia on the pregnancy course as well as its etiology and diagnostics. The treatment principles are discussed.
\end{abstract}

Key words: pregnancy; thrombocytopenia; diagnostic procedures; treatment

Ginekologia Polska 2021; 92, 8: 587-590

\section{INTRODUCTION}

Thrombocytopenia is one of the two most common hematological problems in pregnant women. It is defined as a platelet count (PLT) below $150 \times 10^{3} / \mu \mathrm{L}$, which can lead to acquired purpura. According to various sources, it concerns about $6.6-11.6 \%$ of women in the third trimester [1-3]. It should be noted that even in physiological pregnancy, a decrease of $10 \%$ in the platelet count could be observed [3-5]. Depending on the number of platelets, the following types of thrombocytopenia are distinguished:

- mild thrombocytopenia: PLT 100-150 $\times 10^{3} / \mathrm{uL}$,

- moderate thrombocytopenia PLT 50-100 $\times 10^{3} / \mathrm{uL}$ )

- severe thrombocytopenia (PLT $<50 \times 10^{3} / \mathrm{uL}$ ) [4].

The mechanism of the thrombocytopenia development is based on the impaired production or excessive destruc- tion of platelets. Some causes of this phenomenon involve the immunological processes observed in diseases such as collagenoses, immune thrombocytopenic purpura (ITP), antiphospholipid syndrome, thrombotic microangiopathies, thrombotic thrombocytopenic purpura, haemolytic-uremic syndrome (HUS). Thrombocytopenia may also result from the use of drugs, viral infections, bone marrow dysfunction (bone marrow aplasia), nutritional deficiencies, or disseminated intravascular coagulation syndrome (DIC) $[6,7]$. Pregnant women are additionally exposed to thrombocytopenia due to obstetric reasons. These include preeclampsia, eclampsia, and particularly HELLP syndrome [4, 8]. Although thrombocytopenia in pregnant women usually has a mild course, in some cases a significant decrease in PLT count may lead to severe bleeding. In immune thrombocytopenia, low

Corresponding author:

Monika Ruszala

Department of Obstetrics and Perinatology, Medical University of Lublin, Poland

e-mail: monika.ruszala@wp.pl

This article is available in open access under Creative Common Attribution-Non-Commercial-No Derivatives 4.0 International (CC BY-NC-ND 4.0) license, allowing to download articles and share them with others as long as they credit the authors and the publisher, but without permission to change them in any way or use them commercially. 
levels of platelets in the fetus increase the risk of intracranial bleeding in the perinatal period. Besides, thrombocytopenia may be associated with pregnancy complications or a developing disease regardless of pregnancy. Since it is important to determine the cause of thrombocytopenia and to identify the risk for both the mother and the child [1].

\section{GESTATIONAL INCIDENTAL THROMBOCYTOPENIA}

The most common form of this disease in pregnant women is GIT - gestational incidental thrombocytopenia. The incidence is estimated at $5 \%$, which accounts for $75 \%$ of all diagnosed cases of thrombocytopenia during pregnancy $[3,9]$. Thrombocytopenia is a diagnosis of exclusion. Usually, it is mild or moderate thrombocytopenia with a platelet count above $70 \times 10^{3} / \mu \mathrm{L}$ without the symptoms of purpura which does not occur before conceiving. The platelet count before and at the beginning of gestation usually falls within the normal range and after 1-12 weeks of its completion returns to normal values [10]. Its etiology is unknown. It is believed that GIT is secondary to accelerated platelet destruction and increased plasma volume associated with pregnancy and seems to be a type of physiological thrombocytopenia. It develops usually in the second and third trimester of pregnancy. A mild or moderate decrease in the platelet count due to GIT is not associated with an increase in the ratio of maternal, fetal or neonatal complications, indicating that these conditions do not require additional treatment except careful monitoring of platelet count $[11,12]$.

\section{IMMUNE THROMBOCYTOPENIC PURPURA}

Immune thrombocytopenic purpura (ITP), which may be the threat to the fetus, affects over $4 \%$ of pregnant women $[13,14]$. It is moderate-degree thrombocytopenia with a platelet count below $100 \times 10^{3} / \mathrm{uL}$ before conceiving or at the beginning of gestation and a normal or increased megakaryocyte count in the bone marrow biopsy specimens [15]. During the diagnostic procedures, other systemic diseases, splenomegaly or the use of drugs that may reduce the platelet count should be excluded. Pregnancy does not worsen the course of ITP, but there may be adverse fetal and maternal consequences in some cases. Although rare, spontaneous bleeding is the main maternal risk mainly when the platelet count falls below $20 \times 10^{3} / \mathrm{uL}$ [16]. Antiplatelet antibodies (predominantly lgG antibodies, less frequently $\lg M$ ) lead to accelerated platelet destruction. Maternal lgG antibodies can pass through the placenta and bind to fetal platelets which results in the fetal thrombocytopenia development. This is manifested by the appearance of bruises, petechiae, bleeding from the gastrointestinal tract, as well as intracranial hemorrhage in the neonatal period. Con- genital thrombocytopenia during maternal ITP occurs in about $50 \%$ of newborns, and in $12-15 \%$ of newborns, the platelet count is below $50 \times 10^{3} / \mathrm{uL}[16,17]$. Serious hemorrhagic complications are reported in $3 \%$ of newborns, and in less than $1 \%$ of cases, intracranial bleeding occurs. Even if the maternal platelet count is within the normal range, the risk of having a baby with thrombocytopenia is approximately $30 \%$ [2]. Moderate to severe thrombocytopenia can cause a higher risk for both mothers and newborns, and the method of diagnosis, treatment or delivery is still the subject of debate $[2,7]$.

\section{THROMBOCYTOPENIA DIAGNOSIS}

For establishing the cause of thrombocytopenia, it is very important to take a medical history, make physical examination and select appropriate laboratory tests. Based on the medical history, the following questions should be determined:

1. did thrombocytopenia occur before conception?

2. when did thrombocytopenia in the present pregnancy appear?

3. did thrombocytopenia occurred in a child born before?

4. does the offspring develop properly without any neurological problems (delays in psychomotor development, cerebral palsy, epilepsy)

5. is there a positive obstetrical history (miscarriage, stillbirth resulting from hemorrhage to the central nervous system)?

6. is thrombocytopenia an isolated disease or comorbid symptom? [18, 19]

Thrombocytopenia may be a symptom of serious diseases complicating pregnancy itself, such as pregnancy induced hypertension, DIC, thrombotic microangiopathies (thromboembolic syndrome), thrombotic thrombocytopenic purpura [1]. The above-mentioned symptoms are presented in the following classification of the causes of thrombocytopenia during pregnancy.

Classification of thrombocytopenia in pregnancy:

1. Pregnancy-related thrombocytopenia:

- Gestational thrombocytopenia

- Thrombocytopenia during pregnancy-induced hypertension (Gestora)

- HELLP syndrome (hemolysis, elevated liver function tests, low platelets count)

- Acute fatty liver of pregnancy

2. Thrombocytopenia not related to pregnancy:

- ITP

- Systemic lupus

- Phospholipid syndrome

- Drug-induced thrombocytopenia (caused by heparin, gold preparations, quinidine, penicillin, cimetidine, digoxin) 
- Thrombocytopenia in the course of viral infections (viruses that cross-react with platelet antigens, human immunodeficiency virus (HIV)

- Epstein-Barr-virus

- CMV (cytomegalovirus)

- Thrombotic microangiopathy syndrome

- Thrombotic thrombocytopenic purpura

- Hemolytic-uremic syndrome

- DIC (disseminated intravascular coagulation)

- Bone marrow dysfunction (bone marrow aplasia)

- Leukemias

- Aplastic anemia

- Nutritional deficiencies

- Folic acid and vitamin B12 deficiency

- Hypersplenism

- Pseudothrombocytopenia

The basis for the diagnosis of thrombocytopenia in pregnant women is the use of automatic methods for the analysis of blood parameters, in combination with the reticulocytes count and evaluation of peripheral blood smear. Isolated thrombocytopenia is characteristic of both immune thrombocytopenia and gestational thrombocytopenia. There are large platelets in thrombocytopenia, which is indicated by increased platelet ratios - mean platelet volume (MPV) and platelet large cell ratio (P-LCR), which may exceed their norm. An extremely rare reason for the decreased isolated platelet count during pregnancy is sub-type IIB (2BvWD) and platelet type (PTVWD) of von Willebrand disease (VWD), which is the evidence of congenital thrombocytopenia. Thrombocytopenia with increased reticulocytosis is observed during microangiopathy. The assessment of peripheral blood smears is of great importance in the diagnosis. The presence of fragmentocytes and schistocytes in the smear becomes characteristic of thrombotic microangiopathy. Macrocytosis may be associated with myelodysplastic syndrome (MDS) or deficiency of vitamin B12 and folic acid. The presence of tear-shaped blood cells confirms bone marrow fibrosis. The precise evaluation of white blood cells makes it possible to diagnose neoplastic diseases of the blood that cause thrombocytopenia. In the case of isolated thrombocytopenia, the most likely diagnosis is GIT in the second half of pregnancy and ITP in the first half of pregnancy. In both cases, tests should be performed immediately to rule out secondary immune thrombocytopenia and other reasons for the isolated decrease in PLT count [1]. The following list presents the recommended laboratory tests in pregnant women.

Recommended laboratory tests in pregnant women with isolated thrombocytopenia:

1. Complete blood count with platelet and reticulocyte count

2. Peripheral blood smear

3. Hepatic enzymes and bilirubin
4. Direct antiglobulin test

5. Thyroid function tests

6. Antiphospholipid antibodies

7. Antinuclear antibodies

8. Test confirming infections: Helicobacter pylori, HCV, HBV, and HIV

9. Basic coagulation tests

10. Diagnostic tests for type 2BvWD and PTvWD von Willebrand disease.

\section{THROMBOCYTOPENIA TREATMENT}

The goal of ITP treatment in pregnant women is to prevent severe bleeding. Usually, in the second and third trimester, patients with PLT above $20-30 \times 10^{3} / \mu \mathrm{L}$ do not require treatment unless the invasive procedures are indicated. This treatment includes the administration of corticosteroids and intravenous immunoglobulin. Due to possible side effects of corticosteroids, it is recommended to start treatment with small doses, e.g., prednisone 10-20 mg/day for about 7 days, adjusting the dose to PLT count [20]. According to the recommendations of the group of experts on hemostasis of the Polish Society of Hematology and Transplantologists the administration of prednisone in the initial dose of $1 \mathrm{mg} / \mathrm{kg}$ of body weight and its gradual reduction after PLT count increases above $5 \times 10^{3} / \mu \mathrm{L}$. If the immediate increase in the PLT count is necessary, immunoglobulin should be offered at standard doses of $1 \mathrm{~g} / \mathrm{kg}$ of body weight for 1-2 days. After its transfusion, the PLT count increases in $24-48$ hours and this effect lasts for 2-3 weeks. The immunoglobulin infusion can be repeated to ensure the optimal PLT count every 2-4 weeks until delivery. In the case of the resistance to first-line agents, a bone marrow biopsy should be performed to exclude other causes of thrombocytopenia. If the bone marrow is normal and the isolated thrombocytopenia has been revealed or worsened in late pregnancy, the test for the subtype 2BvWD and PTVWD of von Willebrand disease should be performed. The agents considered as safe by the Food and Drug Administration (FDA) in pregnancy with ITP is azathioprine at a dose of $1-2 \mathrm{mg} / \mathrm{kg} /$ body weight, which has a delayed effect [21]. Another drug approved for the treatment of refractory ITP is cyclosporine. However, due to the frequent side effects, it is rarely used. The contra-indicated drugs during pregnancy are as follow cyclophosphamide, vinca alkaloids, mycophenolate mofetil and danazol [1, 22, 23-25].

\section{CONCLUSIONS}

Thrombocytopenia in pregnancy is a mild condition, especially if it occurs in the last trimester. Its most common cause is GIT, and in the first trimester - ITP. Severe thrombocytopenia can be the reason for dangerous, hemorrhagic complications of pregnancy or the exacerbation of comor- 
bid disease. To diagnose the disease, it is essential to take an in-depth history and perform a physical examination. The key element in the diagnosis of thrombocytopenia is to use automated methods of analysis for evaluating the blood parameters.

\section{Conflict of interest}

The authors have no potential conflict of interests to declare.

\section{REFERENCES}

1. Chojnowski K. Postępowanie z małopłytkowością u kobiet w ciąży. Hematologia. 2013; 4(1): 15-23.

2. Burrows RF, Kelton JG. Fetal thrombocytopenia and its relation to maternal thrombocytopenia. N Engl J Med. 1993; 329(20): 1463-1466, doi: 10.1056/NEJM199311113292005, indexed in Pubmed: 8413457.

3. Grzyb A, Rytlewski K, Domańska A, et al. Ciąża powikłana małopłytkowością. Gin Pol. 2006; 77(9): 712-718.

4. Hwa HL, Chen RJ, Chen YC, et al. Maternal and fetal outcome of pregnant women with idiopathic thrombocytopenic purpura: retrospective analysis of 25 pregnancies. J Formos Med Assoc. 1993; 92(11): 957-961, indexed in Pubmed: 7910066.

5. Schwartz KA. Gestational thrombocytopenia and immune thrombocytopenias in pregnancy. Hematol Oncol Clin North Am. 2000; 14(5): 1101-1116, doi: 10.1016/s0889-8588(05)70173-8, indexed in Pubmed: 11005036.

6. McCrae K, Bussel J, Mannucci P, et al. Platelets: An Update on Diagnosis and Management of Thrombocytopenic Disorders. Hematology. 2001; 2001(1): 282-305, doi: 10.1182/asheducation-2001.1.282.

7. Shehata N, Burrows R, Kelton JG. Gestational thrombocytopenia. Clin Obstet Gynecol. 1999; 42(2): 327-334, doi: 10.1097/00003081-199906000 00017, indexed in Pubmed: 10370851.

8. McCrae K. Thrombocytopenia in pregnancy: differential diagnosis, pathogenesis, and management. Blood Reviews. 2003; 17(1): 7-14, doi: 10.1016/s0268-960x(02)00056-5.

9. Burrows R, Kelton J. Thrombocytopenia at delivery: A prospective survey of 6715 deliveries. Am J Obstet Gynecol. 1990; 162(3): 731-734, doi: 10.1016/0002-9378(90)90996-k.

10. MAGANN E, MARTIN J. Twelve Steps to Optimal Management of HELLP Syndrome. Clin Obstet Gynecol. 1999; 42(3):532, doi: 10.1097/00003081199909000-00009.

11. Moise K, Patton D, Cano L. Misdiagnosis of a Normal Fetal Platelet Count After Coagulation of Intrapartum Scalp Samples in Autoimmune Thrombocytopenic Purpura. Am J Perinatol. 2008; 8(05): 295-296, doi: 10.1055/s-2007-999401.
12. Sainio S, Kekomäki R, Riikonen S, et al. Maternal thrombocytopenia at term: a population-based study. Acta Obstet Gynecol Scand. 2000; 79(9): 744-749, indexed in Pubmed: 10993097.

13. McCrae KR, Samuels P, Schreiber AD. Pregnancy-associated thrombocytopenia: pathogenesis and management. Blood. 1992; 80(11): 2697-2714, doi: 10.1182/blood.v80.11.2697.bloodjournal80112697.

14. Silver R, Berkowitz R, Bussel J. Thrombocytopenia in pregnancy. Practice bulletin, No 6. American College of Obstetricians and Gynecologists, Chicago 1999.

15. Cook RL, Miller RC, Katz VL, et al. Immune thrombocytopenic purpura in pregnancy: a reappraisal of management. Obstet Gynecol. 1991; 78(4): 578-583, indexed in Pubmed: 1923158.

16. Gill KK, Kelton JG. Management of idiopathic thrombocytopenic purpura in pregnancy. Semin Hematol. 2000; 37(3): 275-289, doi: 10.1016/s00371963(00)90106-9, indexed in Pubmed: 10942222.

17. Burrows RF, Kelton JG. Pregnancy in patients with idiopathic thrombocytopenic purpura: assessing the risks for the infant at delivery. Obstet Gynecol Surv. 1993;48(12): 781-788, doi: 10.1097/00006254-19931200000003, indexed in Pubmed: 8309660.

18. Uhrynowska M. Małopłytkowość u kobiet ciężarnych i ich dzieci-spojrzenie immunohematologa. Postępy Nauk Medycznych. 2008; 21(12): 823-827.

19. McCare KR. Thrombocytopenia in pregnancy: differential diagnosis, pathogenesis, and management. Blood Reviews. 2003; 17(4): 265, doi: 10.1016/s0268-960x(03)00023-7.

20. Provan D, Stasi R, Newland AC, et al. International consensus report on the investigation and management of primary immune thrombocytopenia. Blood. 2010; 115(2): 168-186, doi: 10.1182/blood-2009-06-225565, indexed in Pubmed: 19846889.

21. Gisbert JP. Safety of immunomodulators and biologics for the treatment of inflammatory bowel disease during pregnancy and breast-feeding. Inflamm Bowel Dis. 2010; 16(5): 881-895, doi: 10.1002/ibd.21154, indexed in Pubmed: 19885906.

22. http://medicines.org.uk/emc/medicine.

23. Subbaiah M, Kumar S, Roy KK, et al. Pregnancy outcome in patients with idiopathic thrombocytopenic purpura. Arch Gynecol Obstet. 2014; 289(2): 269-273, doi: 10.1007/s00404-013-2958-x, indexed in Pubmed: 23852640.

24. Rumi E, Bertozzi I, Casetti IC, et al. Associazione Italiana per la Ricerca su Cancro Gruppo Italiano Malattie Mieloproliferative Investigators. Impact of mutational status on pregnancy outcome in patients with essential thrombocytemia. Haematologica. 2015; 100(11): e443-e445, doi: 10.3324/haematol.2015.131458, indexed in Pubmed: 26250575.

25. Xu X, Liang MY, Wang JL, et al. Clinical features and outcome of pregnancy with SLE-associated thrombocytopenia. J Matern Fetal Neonatal Med. 2016; 29(5): 789-794, doi: 10.3109/14767058.2015.1018169, indexed in Pubmed: 25747951 